\title{
Meta-travel: A critical inquiry into a China study tour
}

\section{Jennifer Riggan}

Arcadia University

\section{Sonya Gwak}

University of Pennsylvania

\section{Joy Lesnick}

Chapin Hall at the University of Chicago

\author{
Kara Jackson \\ McGill University
}

\section{Stacy Olitsky}

Academy for Advanced and Creative Learning, Colorado Springs, CO

\section{Introduction}

Short-term study tours are among the fastest growing of study abroad experiences and serve the largest percentage of students choosing to study abroad. Fifty-six percent of students studying abroad go on short-term study trips lasting anywhere from two to eight weeks (Institute for International Education, 2009). These trips have the advantage of being able to provide study travel experiences to increasingly large numbers of students at the graduate and undergraduate levels because they are cheaper and they are often more convenient and feasible for students. However, these trips are potentially ill-equipped to promote in-depth experiences of another place and culture. As short-term study tours are likely to continue to grow in popularity, it is imperative to look critically at the goals and structures of these programs, not only to explore how participants can have a more intellectually and personally valuable experience, but also to question the political and social implications of short-term study travel.

This paper questions whether participants on short-term study tours typically allow themselves and their understandings about the world to be 
transformed by their experiences or if these brief trips only serve to reify and legitimize preconceived notions and stereotypes about the world. Based on an analysis of U.S. graduate students' experiences on a trip to China, we argue that short-term study tours have the potential to provide a valuable opportunity for participants to deepen their understanding of themselves and their role in the world. However, they can only do so if a critical reflection component is incorporated in the study tour. Specifically short-term study travel can help participants understand the situated and shifting nature of their identities as students and travelers. It can also deepen their awareness of how they are positioned globally as students of a U.S. based institution, and explore how positionality, identity and stereotypes shape their worldview during study tours. By engaging in an intentional, critical reflection process, we argue that participants can experience deeper emotional and intellectual transformation during short-term study tours. We use the case of a study tour to China to propose a framework for reflection during short-term study travel that we call "meta-travel."

Despite the fact that the scope of short-term study tours generally does not incorporate deep cross-cultural reflection, these are still cross-cultural experiences. Furthermore, the potential for misconceptions and biases dominating travel experiences is greater for the participants than in longer tours because of the limited time involved. It is our hope that the processes we outline here will enable participants on short-term study tours to understand that short-term experiences are only the beginning of their learning and that during these experiences they are not so much learning about the place to which they are traveling, but learning to learn from that place and their interaction with that place.

Below we explore what we mean by critical reflection and make a case for why critical reflection needs to be a key piece of study travel. We then discuss the case itself and the processes through which we developed this framework. Next, we discuss several critical incidents from the study tour itself and suggest ways in which the framework illuminates hidden lessons in each incident. Finally we conclude with some suggestions for how this framework might be utilized on other study tours.

\section{Why Reflect? Study, Tourism, and Power}

Study travel experiences, like other forms of tourism and travel, are designed to be consumed by study travelers in a particular kind of way. However, in the case of educational travel, the travel product consumed is designed to affect some form of intellectual transformation as well. This suggests a need to examine both the packaging of "places" visited and assumptions about 
what can be learned from these places. In light of this, we argue that Edward Bruner's (2005) concept of "enlightened tourism" or "reflexive tourism" which could "disrupt tourists understanding of their travel experiences" would be appropriately applied to short-term study-tours.

Although there is a growing literature on study travel, much of the literature tends to focus on macro level discussions of the importance of study travel to the goals of global education and the production of global citizens (Kirkwood, 2001). Little literature exists that critically interrogates issues of identity and power during study abroad experiences although there are some notable exceptions (Mathers, 2008; Dolby, 2004). Although there is some suggestion that as short-term study tours grow, there is a need to incorporate an inter-cultural component, this work generally does not address issues of power, positionality and identity on short-term study tours (Tuleja, 2008).

The roots of study travel as a core part of one's education can be found in the $18^{\text {th }}$ century when elite, mostly male, members of society made "the grand tour" and thereby became more worldly and cosmopolitan. This ideal of acquiring a sense of worldliness and cosmopolitanism through educational travel is still central to the practice of studying abroad. In fact we might argue that what differentiates study travel from other forms of travel and tourism is the notion that study travel is intended to transform students into a person "of the world" - a cosmopolitan—one who is not a mere tourist, but an educated and educational traveler. Luke Desforges (1998) argues that those who can claim that they have "been there" have a particular cache. They gain a great deal of cultural capital through the process of collecting places. He argues that short travel trips often become means of collecting not only information and material goods, but also identities as travelers. Like the early educational travelers of the $18^{\text {th }}$ century, increasing numbers of students travel in order to become cosmopolitan - to claim that they know more than others because they have "been there".

Travel and tourism, while often thought to be neutral leisure activities, ultimately situate cultures and travelers in a relationship in which one is consumed and the other consumes. Tourism often encourages the host country to display and stage "essentialized" aspects of culture in ways that can be easily consumed by outsiders and can be converted to financial capital (Shaw \& Williams 2002; Bruner \& Kirshenblatt-Gimblett, 2005; Burns, 2001). Indeed, many developing countries that lack marketable natural resources assess and reconfigure their landscape and cultural practices as natural resources to attract tourism. Thus, cultural practices become marketable commodities. A place, a people, their institutions and practices are consumed, and often those who are positioned to package the encounter and broker the experience are paid well 
for the cultural products they provide.

Various brokers of travel experiences who are responsible for packaging these experiences often intentionally direct the tourist's or traveler's gaze to particular aspects of "native" culture (Bruner, 2005; Urry, 1990). However, because power is diffusely located throughout relationships, tourists are as much the subject of the gaze as the natives (Cheong \& Miller, 2000). In fact, it is through the gaze of the tourists that locals and brokers are able to provide and create goods and services that meet the expectations of these tourists. In other words, locals and brokers are said to decipher and construct tourists' expectations. The exchange between tourists and locals is ultimately dependent on what the natives choose to share and how to share it (Taylor, 2001). The tourists, the locals, and the intermediary brokers are all agents in the process of creating the tourist experience.

More sophisticated travelers, however, may be wary of experiences that are packaged in particular ways. Wary of packaged experiences, travelers may seek out what they assume to be authentic experiences not realizing that what they take to be authentic may be constructed for their consumption even in the most out of the way places. Authenticity is a key theoretical concept debated throughout the literature on the anthropology of tourism. "Travelers' quests for authentic experience" refers to travelers' beliefs that there is something real or genuine about an experience, culture or object encountered while traveling. Some scholars have critiqued the existence of the real or authentic experience (Gross, 1992; Hobswawm \& Ranger, 1992; Bendix, 1997). They argue that the concept of authenticity is a socio-cultural construction embedded within travelers' expectations (Hobsbawm \& Ranger, 1992). For many tourists and travelers, the way to seek out authentic experiences is to eliminate the broker or intermediary agency, in order to be more local, or more native. Luke Desforges (1998) highlights some ways that travelers attempt to achieve authenticity. For example, they use public transportation instead of tour buses, veer off the beaten path and reject intermediary agencies. In short, Desforges argues that travelers believe that cutting out the broker and trying to emulate the locals somehow makes experience less contrived and therefore more authentic.

All of this suggests that there are complicated processes embedded in what and how travelers label authentic experiences. Thus, we argue, there is deep learning that can occur when travelers examine their feelings towards brokers and their expectations of and encounters with what they take to be an authentic experience. Beliefs about what qualifies as authentic reveal assumptions about what travelers expect to find or seek through their travel experiences. These assumptions often make essential the culture or place visited, casting the "natives" in a particular role while the traveler is cast in a 
different role.

As we will discuss in more detail below, our exploration of the above concepts revealed several interesting and previously hidden patterns on our particular study tour. There was a conflict between the gazes of the study tour participants (tourists) and the Chinese hosts (natives) and complex power dynamics embedded in the framing of the tourist gaze. Chinese hosts had certain assumptions about how to focus the study tourists' gaze and packaged the trip in a particular way in order to do so; however, participants attempted to refocus the gaze around their own sense of what counted as authentic experiences. We show how critical reflection was necessary in order to help participants see both the limitations and nuances of what they learned on and from the trip.

\section{Developing the Meta-travel Framework through Reflection on a China Study-Tour}

\section{The China Study Tour}

In May 2002, eight students from an urban American university spent a total of two weeks in Beijing and Shanghai with the intention of learning about the educational system of China. This tour was designed by this institution's Graduate School of Education's Office of International Programs. It was the first of its kind at this graduate school of education, and was explicitly framed as a pilot tour.

The tour's overarching purpose, as noted in the tour brochure, was to "afford the selected students with an opportunity to observe and learn of China's education first hand.” In particular, the tour designers argued that American educators "have little knowledge of the Chinese education system, including China's current education policy and their efforts at reform." The tour's explicit goals were as follows: (1) to meet with different stakeholders in the Chinese education system and learn about China's educational reform efforts (e.g., influential policy makers, education researchers, principals, teachers, and students); and (2) to learn about Chinese history and visit historic landmarks.

The pilot study tour spent one week in Beijing and one week in Shanghai. It included meetings with ministry officials, professors of education, teachers and students of Beijing's and Shanghai's top elementary and secondary schools, and fellow graduate students of education. Most meetings occurred with representatives of highly-ranked elementary and secondary schools, the normal schools (teacher-training schools), and graduate schools of education. A typical day included at least two school visits, where the tour participants 
met with the principal as well as some teachers and students. Occasionally, participants were invited to observe classes. The tour also included two full days of sightseeing.

The participants were masters and doctoral students from a variety of educational backgrounds, each with different interests and expectations. Most of them chose to go on the trip out of general curiosity about the world and/or about China, an interest in educational travel, and a belief that they could learn something about education through comparative processes. Some participants had an interest in the field of international and comparative education, but none had much background knowledge about China or an explicit interest in studying the Chinese education system.

Because this particular study tour was a pilot program, this case may not be entirely representative of all short-term study tours. The China Study Tour itinerary was similar in design to many other study tour programs organized by American universities. A combination of lectures, school visits, sightseeing, and limited interaction with local hosts is common for many study tour programs. However, unlike many study tours, there were very few preparation sessions before the trip, and a member of the faculty did not accompany the group on the Study Tour. Typically, short-term study tours include greater amounts of preparation than this trip did, and, in fact, this program incorporated enhanced preparation sessions in subsequent years.

Although we do not argue that this case is representative of all study tours, it was an ideal case to generate our reflective framework. The somewhat unpredictable nature of the tour and the fact that participants were somewhat unprepared actually laid bare participants' motivations and assumptions and allowed us to examine the ways in which participants engaged the unexpected. By exploring this case, we argue that engaging in the type of metacognitive reflection that we outline here helps students develop a more nuanced understanding of the place they are visiting and more complex cross-cultural engagement skills, as well as enhancing understandings of global inequities and imbalances and their own global positionality. Despite that fact, that many study tours better inform students about the place they will be visiting ahead of time, the type of reflective process described in this paper remains a necessary and missing part of many study tours.

\section{The Reflective Process}

The meta-travel framework is a product of two years of regular meetings that were initiated by three of the Study Tour participants and two interested fellow graduate students studying social foundations of education. We began 
this research with the intention of offering concrete suggestions to future study tour participants and leaders to help them address the inevitable conflicts and tensions that arise on group travel as well as recognize that systematic, critical reflection on such tensions can be a source of learning. The Study Tour and our subsequent reflections on the study tour serve as our ethnographic object of analysis.

The research methodology employed while conducting this project mirrors the reflexive processes that we believe are critical to incorporate into future study tours. Ideally, meta-travel reflection would occur during the actual travel experience; however, because we were reflecting on a study tour that had occurred some months before beginning work on this paper, we began our process by collecting various types of data about the trip. Data sources include tape recordings of group conversations, written reflections on these conversations, participant trip journals, a focus interview with other Study Tour participants, and an interview with the trip coordinator. The multiple sources of data were analyzed and reflected on using the process of analytic induction to identify initial themes in the data. We reflected upon and analyzed the data in the same way that we recommend that study travelers reflect upon and analyze their experiences. During this process of analysis as well as during the actual writing of this paper, the five co-authors continued to meet weekly to reflect upon the process of analysis. Thus, we were engaged in a deliberate reflexive process, whereby we continually participated in analysis, critical reflection, and hence, reinterpretation (Alvesson \& Sköldberg, 2000).

\section{The Meta-travel Framework}

In light of this reflective process, we found that the following two questions are significant to ask when engaging in group travel for educational purposes.

(1) Who am I/who are we as "study tourists"?

(2) What do we assume we can learn from travel to another place?

Each of these questions is placed in the broader context of the individual and group country of origin, understandings of international relations between the two countries, and understandings of broader global processes.

The first key question that all study tour participants need to ask is: who am I/who are we as study tourists? Depending on the context in which a person finds herself, particular identifiable characteristics of one's self become more or less salient. The process of understanding one's identity within a different society provides an opportunity not simply for learning about this society but for deepening an understanding of the relationship between how 
one is positioned socially and how one positions the "other" in their home place and the new place being visited. In conjunction with exploring who one is in the context of travel, given that a study tour is a form of group travel, it is also critical for participants to reflect on who they are as a group with respect to their travel. There are dynamics that are particular to traveling in, and therefore being identified with, a group that are necessary to interrogate.

The second question of the meta-travel framework involves articulating underlying assumptions/expectations about the experience of being on the study tour. It is necessary to make explicit one's assumptions about the types of things that the tour is designed to study in order to view problems or disappointments during the course of the tour as learning experiences. Rather than evaluate one's experience as "authentic" or "inauthentic," controlled through various brokers or determined by participants themselves, this question suggests that study tour participants should examine what assumptions and experiences have led them to understand and/or characterize a particular type of experience in a certain way.

Figure 1 illustrates the cyclical, reflexive meta-travel framework. Below, we use several incidents from the China Study Tour and explore the ways in which reflection on those incidents, after the fact, was able to yield deeper insight. Ideally meta-travel reflection would be an ongoing process that occurs before, during, and after study tour travel, as participants' answers to the two core questions will change as a result of their experiences, reflections, and discussions. However, in this case, reflection and analysis on these key incidents was done after the participants returned. We present these incidents and what can be learned from them as examples of the kinds of things that can be uncovered through meta-travel reflection.

\section{Question One: Who am I as a study tourist? Who are we as study tourists?}

\section{Incident One: Lowly graduate students or honored guests? Locating ones social position}

Study Tour participants arrived with a variety of identities that shaped the ways in which they encountered and experienced the Chinese education system. This first sub-section highlights how some participants answered the question, "Who am I as a study tourist?" While individuals' reflections varied depending on their different social locations, there were particular patterns that emerged from our data analysis that speak to the ways that reflecting on this question led to deep consideration of power dynamics in travel.

The most striking pattern was the Study Tour participants' surprise at 
being treated like celebrities, rather than as lowly graduate students, as one of the participants described herself. The participants reported feeling as if they were ascribed a higher level of status than they felt they merited as graduate students. The group was often treated to elaborate banquets during which high ranking university and government administrators made presentations and gave gifts. They stayed in impressive on-campus hotel accommodations at two different universities. In Shanghai, participants were assigned private hotel rooms complete with nightly turn-down service. In spite of how appreciative the group was for the hospitable accommodations, some participants reported feeling uncomfortable because the treatment was indicative of a status that they did not feel they deserved. A disconnect existed between the status ascribed to the group and the group members' self-identity as students. Through reflection on this element of identity, authors of this paper were able to question what it means to be American representatives from graduate schools of education in China and to learn how their identities are given particular meanings in different social contexts.

During post-trip reflection, authors of the paper discussed this dilemma with the trip organizer, Li Lien. Li Lien shed light on what was missed by participants at the time. She commented that the hosts were honored that the group would travel so far to learn about their educational system. Li Lien also described her understanding that a great deal of status is ascribed to education and higher education in particular in China, where education is a privilege available to a few; thus the highly educated, such as graduate students, are treated as persons of statures. It is important to note that without broader reflection, participants would not have thought to raise questions about their status in some cases - they felt uncomfortable about it, but did not think to raise questions about positionality or identity on the basis of this discomfort. The meta-travel framework is designed to allow study travelers to explore this very type of question while on the study tour and to ask questions that will better enhance their understandings of who they are and who the group is in a new context.

\section{Incident Two: "She said what?" Understanding positionality through group identity}

The individual identities of the participants, which are multiple and complex in and of themselves, interacted to create a new level of identity the identity of the group. In the case of a study tour from an educational institution, the home institution as well as the hosts' identification of the group as representatives from the home institution shaped the group identity. 
Interesting tensions ensue in a group travel setting in which members of the group feel that they are being represented by others in their group. The desires of some group members to blend in with the natives, by attempting to learn and enact the native 'culture' and language as accurately as possible, clashed with other group members' inability or unwillingness to do this. For example, one group member consistently pronounced "thank you" incorrectly —almost comically_as described by members of the China Study Tour. This comic error turned to escalating embarrassment as individuals reported feeling apprehensive that their individual identities, and their individual desires to show respect for the Chinese culture, were being misrepresented by association with this particular group member. One tour participant articulated the ways in which she felt represented negatively as a group member and as an American:

I was aware that Americans have a reputation in some countries as being rude and self-absorbed. Anytime that I thought a word was mispronounced, or perceived that someone in the group was not appropriately dressed for a meeting, I felt so embarrassed since I knew whatever they were doing reflected on me.

Key to this reflection is Tina's perception that being identified as an American was negative and something she wanted to be distanced from. However, because of the behavior of others in her group, she felt that she was not able to distance herself from what she perceived to be a negative association with American behaviors. Attempting to distance herself from Americans she idealizes a form of cosmopolitan identification that she assumes is more sensitive than the American way of being. In reflection after the study tour, Tina and other group participants realized the ways that their self-identification was framed by the group, but had they been able to reflect on this dynamic while in China, they might have been better able to interrogate whether or not their hosts shared these attitudes and assumptions and could have better situated the notion of being American in the context of China.

\section{Question Two: What do we assume we can learn from travel to another place?}

The ideals of a cosmopolitan worldview, which are core to study travel, often leads to assumptions that there is a similar frame through which cosmopolitans see and explain the world. On the study tour, tour participants assumed certain similarities between American and Chinese outlooks towards education while noting that there were differences as well. Participants' reflections show the 
ways in which both parity and difference were assumed prior to the trip. Abby wrote, "Perhaps it was the desire to see another nation's education system to see if the American system was so truly at risk" informed her desire to go on the trip in the first place Ann said, "The school system also interested me because the philosophy was so different. With the emphasis being placed more on effort than natural or innate ability and I was interested in seeing how that played out in a classroom ..." Tina wrote, "I was interested in looking at how the education system in another country addressed similar issues, such as how students were sorted into schools, how diversity was addressed, and how curricula were structured." Each of these sentiments clearly indicates that participants expected to see differences between China and the United States. However, more importantly these reflections suggest that participants assumed that they would be able to understand these differences against the backdrop of similar ways of describing educational goals and priorities. For example, the sentiments above reflect participants' assumptions that there would be a common meaning ascribed to things such as effort versus natural ability, that there would be a common understanding of what it meant for an education system to be at risk, or a shared definition of a focused student. As we will discuss, participants eventually felt confused and somewhat lost as they failed to witness what they expected to and lacked a language with which to describe the observed educational practices. In sum, they were not able to learn from their experiences as easily as they expected to.

These assumptions of parity between American and Chinese educational outlooks initially blocked participants from developing a deeper understanding about education in China and led to confusion. It was only through later reflection using the meta-travel framework that participants were able to gain a more nuanced perspective. The following incidents elaborate on this theme.

\section{Incident Three: "Where are the bad schools?" Interrogating the Authenticity of Assumptions}

Assumptions about parity of outlook towards education also fed into participant ideas about what an authentic study tour experience would include and the ensuing disappointment when the tour appeared to be brokered and controlled rather than authentic. When we interrogated these assumptions of authenticity, participants were able to learn a great deal more about how assumptions about education itself, and more specifically education research were fundamentally different in China. The tour itself was highly structured and participants perceived that they were being shown only what their hosts wanted them to see. While this may have been the case, on further reflection, participants realized that these assumptions were, in many ways, rooted in the 
identities that participants brought to the trip and were based on a range of professional values promoted in their American graduate school of education.

Organized by the university and restricted to a short timeframe, the China Study Tour was scheduled very tightly to accomplish many things in a limited amount of time and prioritized according to the agendas of the sponsoring institution. While the administrators solicited the participants for input, much of the planning of the China Study Tour was initiated and scheduled by the administrators. Therefore, it would be fair to say that this brokered study tour had a predetermined set of events that structured the participants' experiences.

However, the disconnect between what the participants hoped to see and what they were shown became a source of tension. The most tangible recurring tension occurred around the fact that students on the trip believed that they were being shown only the best schools. Upon reflection, Abby wrote, "Are we learning from the best or learning from the worst? In my opinion I wanted to see the range." The leaders accommodated the participants by taking them to see what the hosts called mediocre schools. In discussing why they asked to see different schools, Abby wrote,

For some reason, the elite showcase schools they planned for us to see weren't good enough. I wanted to see more average schools because I went to, and taught in, an average school. In our graduate school, we are concerned with urban education, which is often far from the elite showcase schools. Perhaps I wanted to see more of the range of schools to get a better idea of the overall system.

Ann said that the focus of her work was on urban education and inequality. It should be noted, however, that while Ann wanted to see more under-resourced schools, she did not feel comfortable asking to change the intended schedule.

I guess because my experience is in teaching in the city...I wanted to see comparable schools, and see how they dealt with students who were not the best students, and if there were comparable problems. I don't know if it would have occurred to me to ask to see different schools. I wouldn't have asked to see something different.

These expectations reflect an underlying value on the part of tour participants that non-elite education, and, in many cases, impoverished or highly troubled schools, are fertile ground for educational research and learning. It would seem that the Chinese hosts, on the other hand, expected 
tour participants to learn from their elite, successful, model schools. The Chinese hosts appeared to be trying to position their education system in a particular way_as a model to be learned from, rather than a system to be learned about. However, this conflicted with participants' sense that an authentic way to study an education system means to study all facets of the system, its strengths and its weaknesses.

The participants did not reflect on their preconceptions that influenced their request to see mediocre schools until they returned to the States. When they did, they noted that their lack of critical reflection while traveling inhibited their ability to uncover a deeper understanding about educational priorities in China. However, they also noted that their assumption that, if they were to see a mediocre school, it would give them authentic knowledge about the Chinese education system, was rather naïve. In fact, in retrospect, they realized that during a short study tour, it would be impossible to learn definitively about the entire Chinese education system and wished they had the chance to reflect more deeply on what they were being shown and why while in China.

\section{Breaking Down Stereotypes about Education in China}

A wide array of experiences and incidents on the trip uncovered latent stereotypes and assumptions that participants had about the Chinese education system as a whole. Participants held assumptions about what it meant to be a doctoral student in China, the prevalence of classroom discipline in China, and ideas that Chinese students were good at math. While traveling, had critical reflection been integrated into the program, participants would have had opportunities to interrogate their assumptions.

One of these opportunities occurred when tour participants had the chance to interact with Chinese graduate students. Tour participants not only felt that an authentic study tour would show all facets and levels of the Chinese education system, but they made assumptions that their Chinese counterparts, graduate students of education, would have a similar perspective on educational study. Abby and Emily indicated that they assumed that the graduate students they would meet would have similar backgrounds to those of their own and their United States colleagues. During one of the sessions, the participants met with graduate students in education at East China Normal University. Abby wrote,

We thought we would gain a great amount of information from communicating with our graduate-level 'counterparts.' Instead, I found that we didn't have much in common with these students at all. Perhaps it was because our group had many teachers in it now pursuing research 
degrees, but it seemed like these graduate students knew very little about schools and classrooms.

Tour participants also experienced a great deal of confusion when they actually encountered the Chinese education system. Tensions arose due to mismatches in expectations about what education should look like in China, and about issues they felt should permeate all discussions of education.

Conversations regarding the issue of testing highlight participants' preconceived notions about educational policy and the ways in which they were challenged by conversations with Chinese educators. At this particular American graduate school of education, graduate students were encouraged to critically interrogate certain educational policies, such as testing. The U.S. participants expected to encounter the same controversy in China. Abby was surprised to hear educational professionals state repeatedly and unequivocally that testing was the fairest way to determine admission into schools and career paths. She wondered if people truly supported testing and was relieved when she finally met someone who was critical. On the other hand, Tina said she thought that maybe such positive views of testing were honest. She had discussed this issue with a Chinese national who was critical of the government, Confucianism, and even the content of the tests themselves, but he thought that the use of standardized tests was a fair way of determining college admissions, since it was an improvement over the use of personal connections to gain access to college. It was difficult for some of the U.S. participants to imagine a graduate-level discussion of educational policies not accompanied by highly critical attitudes toward testing. The participants' comments indicate that they came to the study tour with valorized ideas and assumptions of how to discuss, investigate, and define educational issues such as testing. They did not find that Chinese educational leaders and professionals shared this critical stance; however, participants found themselves confused, rather than informed, by this difference.

Cosmopolitan ideals led to assumptions about the parity between beliefs about good education or good educational research and regarding Chinese education doctoral students and Americans. Ideas about authenticity encompassed not only a quest to experience and collect authentic culture but a desire to see real Chinese schools and to hear the real opinions about the state of education in China. And, because the study tour was hosted by Chinese Universities, brokers played a significant role as they were not only mediators between individual tourists and natives, but they were also representatives of educational institutions, and therefore responsible for carrying out official functions. 


\section{Conclusions and Implications for Future Study Tours}

The purpose of this project was to deconstruct the interpretive frameworks through which people make sense of their travel experiences. We have called this resulting framework that grew out of such deconstruction meta-travel. We argue that through probing one's travel experiences, particularly in relation to a study tour (which assumes that one will come away from the tour having learned something about another educational system), a participant can more fully understand how it is that one's travel experiences are constructed by and through one's available means of making sense of unfamiliar territory and transactions.

Our discussion outlined the complexities inherent in how participants were represented and how they experienced travel. What became explicit through our deliberate reflections, and more so, through our deliberate metareflections, is that the participants approached this trip in a rather unaware manner. While we do not mean to imply that they were intentionally acting in ignorant ways, their lack of a framework from which to approach formal critical reflection while on the trip stunted the depth with which the participants were able to approach their experiences on this study tour. It is the tensions that resulted from different views, and the perceptions of different views, that are worthy of future reflection and analysis. We also argue that the points of congruence offer fertile ground for valuable analysis.

We have argued that using the meta-travel framework is an essential part of educational travel. Not only does it allow participants to become more aware of their travel experiences, but if participants do not engage in the process of challenging their existing assumptions/ stereotypes, there are potentially harmful results. First, as a method of coping with the tension, other group members may help reinforce existing stereotypes and assumptions by reaffirming the strangeness of the unknown and downplaying the disequilibrium that individual participants may experience. Second, if participants do not challenge their existing assumptions, then they are at risk to re-circulate inaccurate information about their experiences abroad.

Participants from the Study Tour returned having learned something about the Chinese education system, yet they were lacking an interpretive framework with which to make sense of why they experienced various tensions or felt conflicts. By working on this project, participants were able to deconstruct their study tour travel experiences. It is our contention that this type of deliberate critical reflection should be one of the key goals of study tours. Participants on study tours should not only be sent off by their home institution to learn about a foreign education system, but should be required to consider the meta-level of their travel experiences. They should place a 
greater emphasis on reflexively examining the value systems, definitions, and roles underlying what it means to be a representative of a Graduate School of Education before, while and after visiting and studying the educational system of, in this case, a developing country in the context of a global society.

\section{References}

Alvesson, M., \& Sköldberg, K. (2000). Reflexive Methodology: New Vistas for Qualitative Research. London: Sage Publications.

Bendix, R. (1997). In Search of Authenticity: The Formation of Folklore Studies. Madison: University of Wisconsin Press.

Burns, P. (2001). Brief encounters: Culture, tourism and the local-global nexus. In S. Wahab \& C. Cooper (Eds.), Tourism in the Age of Globalisation (pp.290-306 ). New York: Routledge.

Bruner, E. (2005). Culture on tour: Ethnographies of travel. Chicago: University of Chicago Press.

Bruner, E. M., \& Kirshenblatt-Gimblett, B. (2005). Maasai on the lawn: Tourist realism in East Africa. In Bruner, E. (Ed.), Culture on tour: Ethnographies of travel (pp. 33-71). Chicago: University of Chicago Press.

Cheong, S. M., \& Miller, M. L. (2000). Power and tourism: A Foucauldian observation. Annals of Tourism Research, 27 (2), 371-390.

Desforges, L. (1998). 'Checking out the planet': Global representations/ local identities and youth travel. In T. Skelton \& G. Valentine (Eds.), Cool Places: Geographies of youth cultures (pp. 176-196 ). New York: Routledge.

Dolby, N. (2004). Encountering an American self: Study abroad and national identity. Comparative Education Review, 42 (2), 150-174.

Gross, D. (1992). The past in ruins: Tradition and the critique of modernity. Amherst: University of Massachusetts Press.

Hobswawm E., \& Ranger, T. (Eds.). (1992). The Invention of Tradition. New York: Cambridge University Press.

Institute of International Education. (2009). Open Doors annual report on international education. Retrieved December 11, 2009, from http:// opendoors.iienetwork.org/?p=150651

Kirkwood, T. (2001). Our global age requires global education: Clarifying definitional ambiguities. Social Studies, 92 (1), 10-15.

Mathers, K. (2008). 'An interplay at specific points': Traveling between California and Cape Town. Tourist Studies, 8 (1), 61-75.

Shaw, G., \& Williams, A. (2002). Critical issues in tourism: A geographical 
perspective (2nd ed.). Cambridge: Blackwell.

Taylor, J. P. (2001). Authenticity and sincerity in tourism. Annals of Tourism Research, 28 (1), 7-26.

Tuleja, E. A. (2008). Aspects of intercultural awareness through an MBA study abroad. Business Communication Quarterly, 71(3), 314-337. Urry, J. (1990). The tourist gaze: Leisure and travel in contemporary societies. London: Sage. 


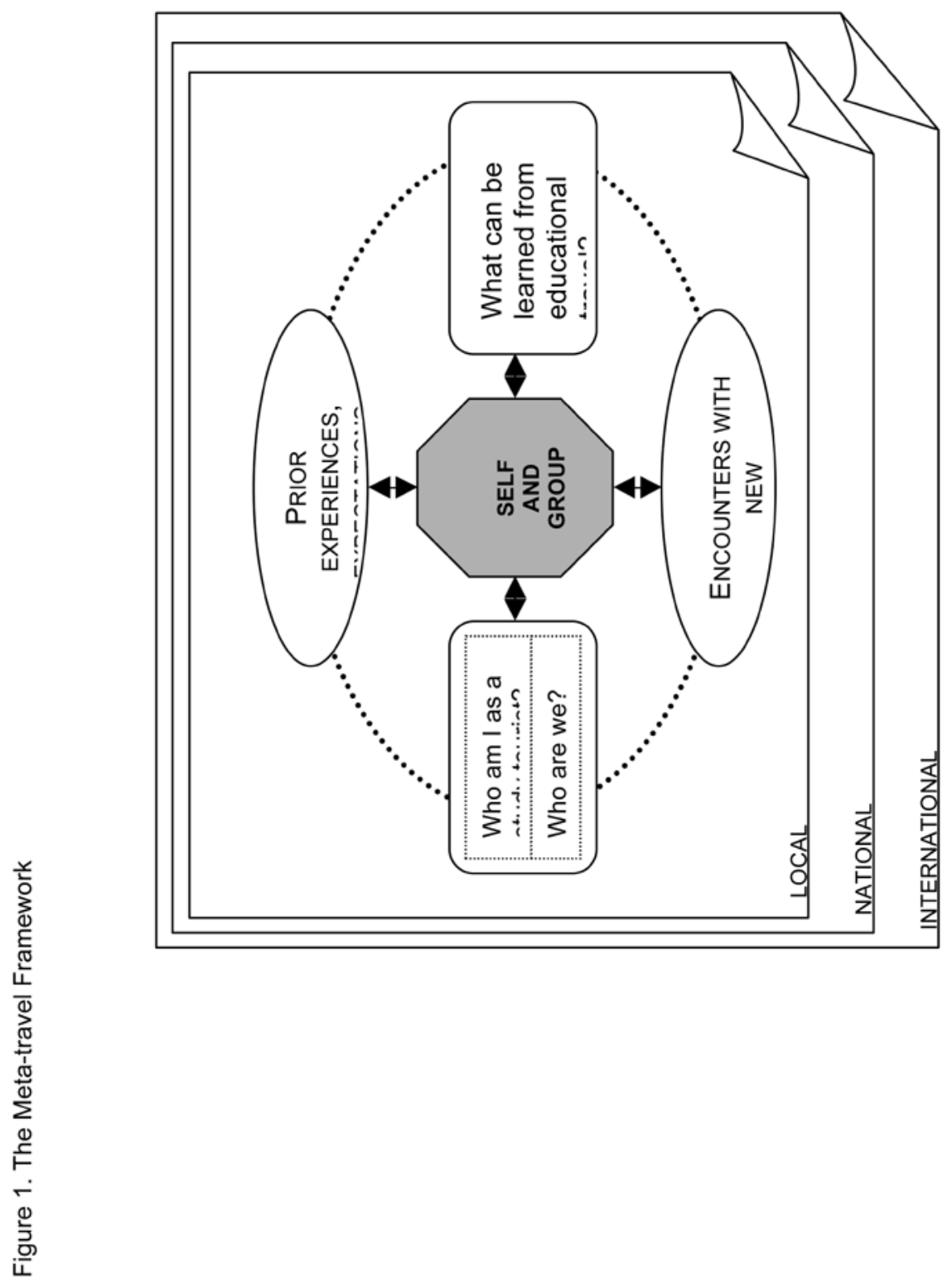

